\title{
Improving Structure of the SLMHM on the Base of the PDCA Cycle
}

\author{
Dmitriy Gakh \\ ORCID: 0000-0002-3007-8891 \\ Institute of Control Systems of ANAS, \\ AZ1141, Bakhtiyar Vahabzadeh str. 68, Baku, Azerbaijan \\ Email:dgakh@sinam.net
}

Keywords: Motivation Model, Learning, Development

\section{Abstract}

Simple Learning Motivations Hierarchy Model (SLMHM) is a theory that attempts to structure the path of learning "growth" with 16 levels where each next level corresponds to higher aims, motives, results, and satisfaction. The SLMHM has been developed to simplify design, control, and evaluate the learning processes.

The SLMHM was first presented at IES-2020 Conference (Gakh, 2020). More detailed research including analysis of internal structure shows that the model should be corrected. "Plan-DoCheck-Act" cycle (PDCA Cycle) is popular in management. This paper describes the SLMHM improved on base of analyses of its similarities with the PDCA Cycle. Description of this research makes SLMHM more comprehend.

\section{Introduction}

Education is a foundation stone of the society. Learning processes in their turn are the main part of education. A good learning motivation model is a tool allowing to solve many problems in education.

The SLMHM has been initially developed on base of though experiment and needed further research and prove in practice. "Plan-Do-Check-Act" cycle (PDCA Cycle) in its turn is well known and was proven in practice. Thus all similarities that are exists between the SLMHM and the PDCA Cycle could indirectly confirm the practical value of the SLMHM.

Another issue relates to internal structure of the SLMHM. A clear and integral internal structure will allow, on the one hand, to have a "beautiful" model. On the other hand, obviously, it will allow the development of clearer and holistic processes.

This paper describes analyses of internal structure of the SLMHM and its similarities with the PDCA Cycle. Improved structure of the SLMHM is also presented. 


\section{Literature, Theoretical Background and Research Questions}

(Moen \& Norman, 2009) showed that "Plan-Do-Check-Act" cycle (PDCA Cycle) was born as the result of evolution of science evolution started from Galileo and Francis Bacon (1561-1626). Although the PDCA Cycle relates to management, its originality from the science allows to analyze its possible similarities with the SLMHM. (Langley, G. Nolan, and K. Nolan elaborated the improvement cycle and called it the PDSA Cycle. The use of word "Study" instead of word "Check" emphasizes that the purpose of third phase is to build new knowledge (Moen \& Norman, 2009)). And the phase "Act" corresponds to adopt that was built at previous stage. This fact shows relation of the PDSA Cycle to the learning and endorsed that relationship between the PDSA Cycle and the SLMHM should be analyzed.

Information, as well as Information and Communication Technologies (ICTs) play an increasingly important role in the development of modern society. Modern society forms new kind of society called as "Information Society". In its importance, information can be put on a par with material and financial resources. Today, modern society is a subject of extensive research having holistic and system approaches covering all dimensions of the information society (Ziemba, 2013).

Education is a foundation stone of the society. Intensive development of technologies and globalization have led to challenges that require new approaches to solving emerging problems. The phenomena associated with the so-called "Technological Singularity" and the associated accelerated development processes (Eden et al., 2012) require adequate responses from the society and education. Education should be flexible enough to satisfy needs of modern society. At the same time education should be cheap, available, and of high quality. Achievement of these qualities is not easy although these qualities impact the society future.

Successful learning directly depends on the learners' motivation. Educators can determine through knowledge about students' motivation which students are likely to be involved in and benefit from education. Effective instructional design cannot be completed without the understanding of learners' motivation. According to the research students' motivational beliefs and learning strategies influence academic outcomes (Clayton et al., 2010).

Deep learning is significantly influenced by the students' intrinsic and extrinsic motivations. The research also shows that a deep learning approach is much more than spending a time on studying (Everaert et al., 2017). Successful students's learning, learning strategies, and selfregulated learning are consistently depends on their motivation (Rashid \& Rana, 2019). There are positive and significant relationships between motivation factors and learning strategies. Motivation variables can significantly predict learning strategies of the students (Hariri et al., 2021). These facts show the importance of motivation in learning processes at different qualitative levels.

In order to improve learning the educators, first of all, should target motivation. Motivation can be considered as an act or process, stimulus, force, influence, incentive, conditions or drive (Williams, K. \& Williams, C., 2011). Motivation was selected as a key factor of successful learning (Gakh, 2020).

The following research questions should be answered after analyzing of possible relations between the SLMHM and the PDCA Cycle:

RQ1: Does the original SLMHM need improvement?

RQ2: Has the SLMHM have similarities with the PDCA Cycle?

RQ3: In what domains the SLMHM can be applied? 


\section{Research Methodology}

This research is based on the comparative design (Walliman, 2011) because it finds analogies in the SLMHM and the PDCA Cycle. Descriptive design does also takes place because found findings are described.

According to the abstraction levels (Gakh, 2020; Walliman, 2011), SLMHM is a theory. This paper continue to describe this theory on the conceptual levels. It also attempts to describe indicators, confirming the conceptions. SLMHM can be considered as a 16-level scale where the level number can be classified as a variable value. In this context the variable can be considered as a motivation level, level of a learning process, level of a scientific breakthrough, and so on. Breaking the complex learning process into several simple processes and studying of them can show values that form matrix or tree-like structures. This approach allows deeper considering more variables and modeling.

\section{Findings}

Feasibility of this study is concluded in fact that the number of levels in the SLMHM is 16 and number of steps in the PDCA Cycle is 4 . It means that 16 SLMHM can be grouped by 4 and compared with the PDCA steps. The analyses showed that original SLMHM structure should be improved. Improvements included relocation and renaming of some levels.

In this chapter Improved Structure of the SLMHM, then it structural analyses and comparison with the PDCA Cycle are presented. Comparing of different conceptions, represented by the SLMHM levels and the PDCA steps resulted to get some kind of judgment. Strictly speaking, these judgments cannot be an objective result. But they allows to more understand the SLMHM model, its relation to the PDCA Cycle, and consequently how to apply SLMHM in practice.

\section{Improved Structure of the SLMHM}

Improved Structure of the SLMHM is presented in Table 1.

Table 1. Levels of improved SLMHM structure.

\begin{tabular}{|l|l|l|}
\hline Level & \multicolumn{1}{|c|}{ Name } & \multicolumn{1}{c|}{ Description } \\
\hline 1 & Desire & $\begin{array}{l}\text { This is the minimal and fundamental motivation. It can be presented as } \\
\text { a thought or an idea. }\end{array}$ \\
\hline 2 & Intention & $\begin{array}{l}\text { This is the second motivation. However, the previous motivation is also } \\
\text { presented on this level. Desire is the fundamental motivation because it } \\
\text { can exist without intention. Intention in its turn cannot exist without } \\
\text { desire. Desire can be extrinsic, like all motivations. }\end{array}$ \\
\hline 3 & Abilities & $\begin{array}{l}\text { After having intention, one starts looking for abilities to satisfy it. } \\
\text { Motivation for looking for abilities cannot exist without intention and } \\
\text { desire. }\end{array}$ \\
\hline 4 & Action & $\begin{array}{l}\text { This motivation level represents motivation for physical start of the } \\
\text { learning process. Obviously, motivations of previous levels should also } \\
\text { exist at this level. }\end{array}$ \\
\hline 5 & Evaluation & The learning process should not take place by itself. It should lead to the \\
\hline
\end{tabular}




\begin{tabular}{|c|c|c|}
\hline & & $\begin{array}{l}\text { results. Thus, the learning process needs evaluation. Evaluation can also } \\
\text { include some kind of explicit feedback, but not for all cases. For } \\
\text { example, machine learning component may not require explicit } \\
\text { feedback in case of unsupervised learning. }\end{array}$ \\
\hline 6 & Improvement & $\begin{array}{l}\text { The evaluation presented at previous level should serve to get the } \\
\text { highest worth. Evaluation can take place once and does not relay on } \\
\text { improving the knowledge (a final exam, for example). At this level, the } \\
\text { evaluation should influence the learning process in way to improve } \\
\text { knowledge and skills. Is there motivation to start iterative, repeating } \\
\text { learning process? Supervised machine learning is an example where } \\
\text { improvement is required. }\end{array}$ \\
\hline 7 & Alternatives & $\begin{array}{l}\text { The learners' skills and personal qualities as well as the situations } \\
\text { where the learners' knowledge and skills should be applied are quite } \\
\text { different. In order to have a higher improvement rate (motivation level } \\
\text { 6) different alternative learning options should be introduced. These } \\
\text { options can include teaching methods, exercises, cases, teachers, and so } \\
\text { on. The more learning alternatives are in the learning process the higher } \\
\text { the probability of the highest influence (or result) can be achieved. } \\
\text { Alternatives also influence a number of improvement loops (motivation } \\
\text { level 6). For the science it includes considering different cases to test } \\
\text { the findings. For AI it equals to size and dispersion of the training set } \\
\text { (such variables as diversity index could be used). It can also include the } \\
\text { structure of the neural network that contains different alternative sub- } \\
\text { structures and the restrictive rules (in case of the AI amotivation). }\end{array}$ \\
\hline 8 & Innovation & $\begin{array}{l}\text { The innovation is the most valuable achievement (result), available at } \\
\text { this level (or levels } 1-8 \text {, because all previous motivations exist at this } \\
\text { level). It can be also considered as the level where an invention can } \\
\text { appear. For AI it is level where it can produce something valuable that } \\
\text { did not exist before. }\end{array}$ \\
\hline 9 & Reward & $\begin{array}{l}\text { One can achieve motivation level 8, the Innovation once or may be } \\
\text { twice. In order to support it at this level and increase the possibility of } \\
\text { subsequent innovations, the innovation should be rewarded. The reward } \\
\text { can be a monetary compensation, promotion, social recognition, } \\
\text { autonomy, authority or something else. This statement is true for } \\
\text { learners, teachers and scientists. For AI it can relate to some type of } \\
\text { feedback (one example was presented by Schmidhuber (2010)). }\end{array}$ \\
\hline 10 & Optimization & $\begin{array}{l}\text { In order to have the higher reward and lower expenditure the } \\
\text { learning/research process should be optimized. This optimization can } \\
\text { include structuring of resources, team, promises, targets, processes and } \\
\text { so on. This optimization is "internal optimization" that relates to } \\
\text { controlled components. For AI it can correspond to software/hardware } \\
\text { optimization. }\end{array}$ \\
\hline 11 & Synergy & $\begin{array}{l}\text { This level corresponds to the motivation of the team work and the } \\
\text { cooperation with the partners/customers. It could be considered as a } \\
\text { holistic optimization, as an optimization including synergetic methods } \\
\text { to achieve a dramatic productivity increase. This level includes } \\
\text { "optimization" of interaction both controlled and uncontrolled } \\
\text { components. For AI it can include total optimization and change } \\
\text { structural/operational conception. }\end{array}$ \\
\hline 12 & Extraordinary & $\begin{array}{l}\text { Extraordinary. At this motivation level conditions to achieve } \\
\text { extraordinary invention appears (satisfaction of all previous levels). } \\
\text { Impact of the extraordinary invention is wider and more important than }\end{array}$ \\
\hline
\end{tabular}




\begin{tabular}{|c|c|c|}
\hline & & $\begin{array}{l}\text { the innovation is. In the science it is the great breakthrough in research. } \\
\text { For AI it is a result that can impact the entire humanity. }\end{array}$ \\
\hline 13 & Information & $\begin{array}{l}\text { At this level both the internal and the external information flows } \\
\text { become the key motivation. If something extraordinary has been } \\
\text { invented/achieved, other people should know about it. It should be } \\
\text { presented for all parties for review, evaluation, and implementation. } \\
\text { This level contain motivation for different relevant data gathering } \\
\text { actions and processing. In AI world this level can relate to the Big Data. }\end{array}$ \\
\hline 14 & Streamlining & $\begin{array}{l}\text { This motivation level is also optimization of some kind. But this } \\
\text { optimization is deeper and wider than level } 10 \text {. Level } 10 \text { optimization } \\
\text { mainly relates to the productivity increase. Streamlining mainly relates } \\
\text { to internal improvements aimed to improve information processing. The } \\
\text { aim here is the full control of all informational flows. This level can } \\
\text { relate to AI's Data Mining components. }\end{array}$ \\
\hline 15 & Expansion & $\begin{array}{l}\text { Streamlining allows handling huge amounts of unstructured } \\
\text { information. This ability enables the next ability - to expand. The } \\
\text { motivation on this level realizes wishes to cover as many spheres of } \\
\text { human live as possible (We will consider expansion from } \\
\text { anthropocentric point of view. So other spheres are also considered if } \\
\text { they relate to human interest). An example of expansion motivation is } \\
\text { Frederick Taylor's statement about scientific management - } \\
\text { "fundamental principles of scientific management are applicable to all } \\
\text { kinds of human activities, from our simplest individual acts to the work } \\
\text { of our great corporations" (Blake \& Moseley, 2011). Appearance of this } \\
\text { motivation in AI agent is dangerous for human, because it can lead to } \\
\text { unmanaged improvement of AI. }\end{array}$ \\
\hline 16 & Totality & $\begin{array}{l}\text { From anthropocentric point of view this is the last and greatest level } \\
\text { covering all spheres of human life for long time. It is unacceptable } \\
\text { motivation for AI, because if it appears, AI agent starts covering } \\
\text { everything available and developing to replace the humans. }\end{array}$ \\
\hline
\end{tabular}

\section{Structural Analysis}

Analysis of the internal structure shows some interesting findings. If place levels in $4 \times 4$ matrix in way, presented in Table 2, one can see some similarities between levels in rows and columns.

Table 2. SLMHM levels structured to $4 \times 4$ matrix.

\begin{tabular}{|l|l|l|l|l|}
\hline Rows / Columns & \multicolumn{1}{c|}{ Column 1 } & \multicolumn{1}{c|}{ Column 2 } & \multicolumn{1}{c|}{ Column 3 } & \multicolumn{1}{c|}{ Column 4 } \\
\hline Row 1 & Desire & Evaluation & Reward & Information \\
\hline Row 2 & Intention & Improvement & Optimization & Streamlining \\
\hline Row 3 & Abilities & Alternatives & Synergy & Expansion \\
\hline Row 4 & Action & Innovation & Extraordinary & Totality \\
\hline
\end{tabular}

The similarities could be as the following:

- Considering the Reward as a feedback, the levels in the Row 1 show some kind of information. So, the Desire is an idea or thought, that is an information in the mind, the Evaluation is the comparison of information gathered from the Action with the expected values, the Reward is the feedback, and Information does not require an explanation. At the same time one can cay that the levels in the Row 1 show some kind of evaluation. In this case the Desire is an appreciated idea, the Reward is a bonus for evaluated achievement or feedback, and the Information is evaluated or measured given; 
- Considering the Intention as a selection of major idea or thought from other thoughts and its strengthening, levels in the Row 2 show some kind of improvement or strengthening;

- The levels in the Row 3 show some kind of ability. The Alternatives, Synergy, and Expansion can be considered as measures giving ability. The levels in the Row 3 can be also considered as plurality. The Abilities represent a set of the entities allowing to start the learning process. The Alternatives are a set of the entities/possibilities to select better options for better learning and improving iterative learning. The Synergy represents parties arranged in order to have the best results. The Expansion represents multiplicity of entities to be covered;

- The levels in the Row 4 show some kind of result, or finish of previous stages. So, the Action is the start of the learning process, the Innovation and the Extraordinary represent invention, and the Totality is the highest achievement;

- Each column can be considered as a complete part of a learning cycle. Thus, one can speak about ability to divide the 16 levels up to the 4 stages.

The $4 \times 4$ matrix of the SLMHM can be compared to the PDCA cycle. If one juxtaposes the phases of this cycle with the rows of Table 2, the result is the following (see Table 3): the Plan equals to the Row 1; the Do equals to the Row 2; the Check equals to the Row 3; the Act equals to the Row 4. At the first look there is no direct match. But taking into account that the phase Do shows the nature of the process the SLMHM nature is the improvement. It corresponds to the learning process where the latter one equals to learner's improvement. In this case the phase Plan corresponds to the improvement plan, the phase Check corresponds to the study of abilities to improve and build new knowledge about the improvement. (Langley, G. Nolan, and K. Nolan elaborated the improvement cycle and called it the PDSA Cycle. The use of word "Study" instead of word "Check" emphasizes that the purpose of third phase is to build new knowledge (Moen \& Norman, 2009)). And the phase Act corresponds to adopt that was built at previous stage.

Table 3. SLMHM 4x4 matrix aligned to PDSA / PDSA phases.

\begin{tabular}{|l|l|l|l|l|}
\hline Phases & \multicolumn{1}{|c|}{ Plan } & \multicolumn{1}{c|}{ Do } & \multicolumn{1}{c|}{ Check / Study } & \multicolumn{1}{c|}{ Act / Adopt } \\
\hline Plan & Desire & Evaluation & Reward & Information \\
\hline Do & Intention & Improvement & Optimization & Streamlining \\
\hline Check / Study & Abilities & Alternatives & Synergy & Expansion \\
\hline Act / Adopt & Action & Innovation & Extraordinary & Totality \\
\hline
\end{tabular}

Thus, SLMHM complies with PDCA cycle. It contains 4 types of PDCA cycle according to 4 columns of Table 2. It means that the learning process can be organized cyclically. The learning processes of the 1st level can be modeled with 4 first levels of SLMHM. Such learning processes are aimed to prepare educated people. Improvement of the learning processes supposes including of 8 first SLMHM levels, or two cycles. Such learning processes are aimed to produce innovations. The learning processes using 12 first SLMHM levels, or 3 cycles are aimed to produce extraordinary inventions. And the most advanced learning processes using all 16 SLMHM levels, or all of its cycles can pretend to produce inventions that impact all human activities for long time (total coverage).

Other interesting findings can be discovered if PDCA cycle phases are juxtaposed with columns of Table 2. In this case the first SLMHM cycle containing its 4 first levels, forms the phase Plan. There is no explicit conformity between these levels and the planning. But taking into account that SLMHM levels 1, 2, and 3 (the Desire, the Intention, and the Abilities) are more preparatory levels and only one - the level 4 (the Action) is the start of real learning process, it can be considered as a planning phase. 
In the similar manner SLMHM levels 5,6,7, and 8 can be considered as corresponding to the phase Do. Indeed, all these levels can be improved (the Evaluation gives feedback for the improvement, the Alternatives creates abilities, and the Innovation introduces something for improvement of something else). SLMHM levels 9,10,11, and 12 can be considered as levels corresponding to the phase Check. These levels are characterized as "improvement of improvement". It means that previous phase supposes improvement of the learning process results. But the phase Check supposes improvement of the learning process itself. SLMHM levels 13,14,15, and 16 can be considered as levels corresponding to the phase Act. These levels are characterized as adopting of knowledge of the learning process that was built at the previous stage.

\section{Discussion and Application}

Direct juxtapose the SLMHM levels and phases of the PDCA Cycle should be correctly interpreted. Each level of the SLMHM is unique and is qualitatively different from one another. Thus generalization introduces certain distortions. As the result, the SLMHM levels and phases of the PDCA Cycle cannot be compared accurately enough, in the way it can be done for let's say numeric values.

Although the SLMHM is a motivation theory, it can be applied for other conceptions - needs, satisfaction of needs, processes, technologies, and so on. This study shows that the SLMHM can be used to design processes (at least together with the PDCA Cycle). Application of the SLMHM in different domains is a subject for further research. Issues related to Education, Sustainable Development, and Motivation are of particular interest.

Product in production is something that is appeared during phase Do of the PDCA Cycle. Thus one can say that the phase Do determines the result and the sphere where PDCA Cycle is applied. For the case, presented in Table 3, phase Do relates to some kind of improvement or strengthening (what follows from similarities in the Row 2 of Table 2). Thus for this case one can say that the SLMHM represent model for some kind of improvement or strengthening process. In case if the phase Do is aligned to the Evaluation, Improvement, Alternatives, Innovation (see column Do in Table 3) the main purpose of the SLMHM could be getting an innovation (as the result of phase Do - the Innovation).

The PDCA Cycle represents iterative process. Levels of the SLMHM can be juxtaposed with the different SLMHM levels in different ways. Table 4 represents an interesting case, started from checking of existing situation (or studying), acting (or adopting), planning and doing. Juxtaposing of this sequence to the SLMHM levels seems more comprehend.

Table 4. One of alternative alignment of SLMHM 4x4 matrix to PDSA / PDSA phases.

\begin{tabular}{|l|l|l|l|l|}
\hline Phases & Check / Study & \multicolumn{1}{c|}{ Act / Adopt } & \multicolumn{1}{c|}{ Plan } & \multicolumn{1}{c|}{ Do } \\
\hline Check / Study & Desire & Evaluation & Reward & Information \\
\hline Act / Adopt & Intention & Improvement & Optimization & Streamlining \\
\hline Plan & Abilities & Alternatives & Synergy & Expansion \\
\hline Do & Action & Innovation & Extraordinary & Totality \\
\hline
\end{tabular}

There are different ways where phases of the PSCA Cycle can be juxtaposed with levels of the SLMHM. A t the same time order of the phases and levels does not change. Each way of juxtapose has its own meaning. This fact allows us to consider that the model can be applied in a wide range of real situations. 
One can hypothesize that the level of the SLMHM represent frequency of relation phenomena. In this way Desire is the most frequent. Not all desires lead to the Intention, thus the Intention is less frequent. Not all intensions lead to look for Abilities, thus the Abilities is more less frequent. Arguing in this way, one can further conclude that Totality is the rarest level. This picture corresponds also to the sequence of possible cycles (see Picture 1):

- Desire->Intention->Desire->Intention-> ...;

- Desire->Intention-> Abilities-> Desire->Intention-> Abilities-> ... ;

- Desire->Intention-> Abilities->Action-> Desire->Intention-> Abilities->Action-> .. ;

- So on.

It is obvious that frequency of phenomena relating to higher levels is less, because all previous levels must have place (in words of motivation - satisfied). Anyway, presence of cycling structures in the SLMHM is an evidence that the model can be applied for iterative processes. This quality of the SLMHM shows that adaptability of designed processes can be increased.

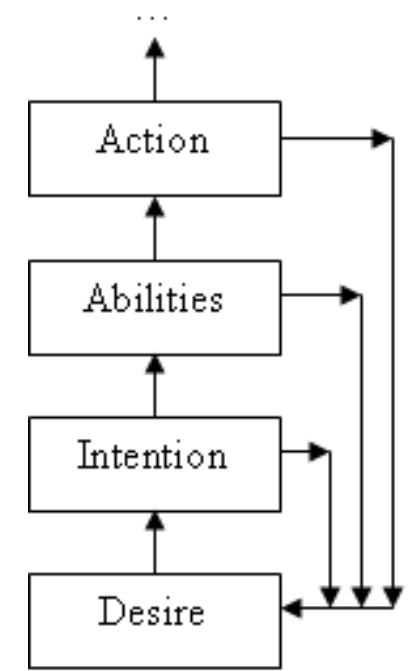

Picture 1. The SLMHM in cycles.

Application of the SLMHM requires understanding of what can be achieved at the maximum as a goal. In this case the goal will correspond to the Totality SLMHM level. However, formulating such a goal is difficult for various reasons. First, something can be accidentally ignored.

Secondly, an incorrectly formulated goal can become a limitation (there are cases where the benefits of the process exceeded expectations, both quantitatively and qualitatively).

But the SLMHM allows to correct goals and expectations when develop from lower levels to higher ones. For example the Alternatives allows to supply additional options/elements that will enrich further levels and make their implementation/satisfaction more possible.

\section{Conclusion}

The main value of this research is the improved SLMHM structure. Another value is description of its relation to the PDCA Cycle. Summary of this relation can be presented as:

- Structure of improved SLMHM is more clear and integral, comparing to the initial version;

- SLMHM can be applied for iterative processes;

- SLMHM can be applied for cases where goals are not formulated well;

- SLMHM can be used in wide range of domains. 
Improved SLMHM is more deeply justified in this research comparing to the original SLMHM. This paper does not discuss differences, rather it justifies the improved structure presented in Table 1. Since the original SLMHM structure was created on the basis of a thought experiment, it is less substantiated. Improved SLMHM structure should be used in future works.

Improved SLMHM structure is considered compliant to PDCA Cycle. Thus one can claim that SLMHM can be applied in these domains, where PDCA Cycle can. At the same time this application should be studied and described for each case.

\section{Limitations and Recommendations}

Although the SLMHM is improved, it remains a theory. Moreover, some statements of the SLMHM are hypotheses. So, further research and practical prove of the SLMHM are necessary. At the same time the model can be used in wide range of applications. The most interesting cases, where application of the SLMHM should be studied include, but not limited by:

- Education. Application of the SLMHM with prioritize of the adaptability;

- Smart City. Application of the SLMHM because there is no definition what Smart City is, and consequently there is no defined goals;

- Sustainable Development. Use of the SLMHM to evaluate development level and plan the growth;

- Artificial Intelligence. Use of the SLMHM for study, analyses, motivation, and control.

SLMHM has been developed by means of though experiment. Thus, the model is subjective because it is based on though limitation of the researcher. One can say that this limitation simplifies actual situation. Thus the model can be considered as one providing ability to simplify a complex processes and analyze them in structured manner.

SLMHM does not provide information how to motivate and how to achieve the satisfaction. But it can be used to analyze the problems associated with the motivation and satisfaction and understand what kind of motivation is need to achieve a higher quality level in the learning process.

\section{References}

Gakh, D. (2020). A review of the simple learning motivations hierarchy model. Proceedings of the XII International Scientific-Practical Conference: Internet-Education-Science 2020, 225-227.

Blake, A. M., \& Moseley, J. (2011). Frederick Winslow Taylor: One Hundred Years of Managerial Insight. The International Journal of Management, 28 (4/2), 346-253.

Clayton, K., Blumberg, F., \& Auld, D. (2010). The relationship between motivation, learning strategies and choice of environment whether traditional or including an online component. British Journal of Educational Technology, 41(3), 349-364. https://doi.org/10.1111/j.14678535.2009.00993.x

Eden A. H., Steinhart E., Pearce D., \& Moor J.H. (2012) Singularity Hypotheses: An Overview. Singularity Hypotheses. The Frontiers Collection. https://doi.org/10.1007/978-3-642-32560-1_1

Everaert, P., Opdecam, E., \& Maussen, S. (2017). The Relationship between Motivation, Learning Approaches, Academic Performance and Time Spent. Accounting Education, 26(1), 78-107. https://doi.org/10.1080/09639284.2016.1274911 
Hariri, H., Karwan, D. H., Haenilah, E. Y., Rini, R., \& Suparman, U. (2021). Motivation And Learning Strategies: Student Motivation Affects Student Learning Strategies. European Journal of Educational Research, 10(1), 39-49. https://doi.org/10.12973/eu-jer.10.1.39

Moen, R., \& Norman, C. (2009). Evolution of the PDCA cycle. Asian Network for Quality Conference.

Rashid, S., \& Rana, R. A. (2019). Relationship between the Levels of Motivation and Learning Strategies of Prospective Teachers at Higher Education Level. Bulletin of Education and Research, 41(1), 57-66.

Schmidhuber, J. (2010). Formal Theory of Creativity, Fun, and Intrinsic Motivation. IEEE Transactions on Autonomous Mental Development, 2(3), 230-247. https://doi.org/10.1109/TAMD.2010.2056368

Walliman, N. (2011). Research methods. The basics. Routledge.

Williams, K. C., \& Williams, C. C. (2011). Five key ingredients for improving student motivation. Research in Higher Education Journal, 121-123.

Ziemba, E. (2013). The Holistic and Systems Approach to the Sustainable Information Society. Journal of Computer Information Systems, 54(1), 106-116.

https://doi.org/10.1080/08874417.2013.11645676 